\title{
Safety and Efficacy of Higher Order Multifetal Pregnancy Reduction: A Single-Center Retrospective Study
}

\author{
Yan Liu, MM ${ }^{1,2}$ Xie Tong Wang, MD, $\mathrm{PhD}^{1}$ \\ Yan Tun Wang, $\mathrm{MD}^{1}$ \\ 1 Department of Obstetrics and Gynecology, Shandong Provincial \\ Hospital, Cheeloo College of Medicine, Shandong University, Jinan, \\ Shandong, China \\ 2 Department of Obstetrics and Gynecology, Shandong Qianfoshan \\ Hospital, Cheeloo College of Medicine, Shandong University, Jinan, China \\ Am J Perinatol Rep 2020;10:e228-e233.
} Hong Yan Li, MD ${ }^{1}$ Hai Yan Hou, MD ${ }^{1}$ Hong Wang, MD ${ }^{1}$

\begin{abstract}
Address for correspondence Xie Tong Wang, MD, PhD, Department of Obstetrics and Gynecology, Shandong Provincial Hospital, Cheeloo College of Medicine, Shandong University, 324 Jingwu Road, Jinan 250021, China (e-mail: xietongwangg@126.com).
\end{abstract}

\begin{abstract}
Keywords

- higher order multifetal pregnancy

- multifetal pregnancy reduction

- perinatal outcome

- multiple pregnancies
\end{abstract}

Objective This research was aimed to study the safety and efficacy of higher order multifetal pregnancy reduction (MFPR).

Study Design This was a retrospective study of patients from an academic maternity center between 2005 and 2015. We evaluated outcomes of 131 consecutive patients who underwent higher order MFPR (quadruplets and greater). MFPR was performed at 11 to 18 weeks of gestation in all cases. In total, 122 of 131 cases of higher order multiple pregnancy were reduced to twins. We discuss the perinatal outcomes of patients who underwent higher order MFPR, followed by a comparative analysis between the 122 cases of MFPR that were reduced to twins and 101 cases of nonreduced twin pregnancies.

Results The study included 104 sets of quadruplets, 20 sets of quintuplets, 5 sets of sextuplets, 1 set of septuplets, and 1 set of octuplets. The perinatal outcomes of the 131 cases were as follows: pregnancy loss, preterm deliveries at 28 to $33\left(+{ }^{6 / 7}\right)$ weeks, and preterm deliveries at 34 to $36\left(+{ }^{6 / 7}\right)$ weeks occurred in $23.66,9$, and $37 \%$ of cases, respectively. The mean time of delivery was $36.56 \pm 1.77$ weeks, and mean birth weight was $2,409.90 \pm 458.16 \mathrm{~g}$, respectively. A total of 122 cases that were reduced to twins were compared with nonreduced twins. The pregnancy loss rate for reduced twins was significantly higher than that for nonreduced twins. The preterm labor rate, mean delivery week, mean birth weight, birth-weight discordance, incidence of gestational diabetes mellitus, and pregnancy-induced hypertension were not significantly different between the groups $(p>0.05)$.

Conclusion Perinatal outcomes were significantly improved by reducing the number of fetuses in higher order multifetal pregnancies. This study involved a large, diverse sample population, and the results can be used as a reference while conducting prenatal counseling.
In the last few decades, clinical evaluation of global variation in the incidence of multifetal pregnancy is largely a result of assisted reproduction technologies (ART). ${ }^{1}$ In the United States alone, the rate of triplets and higher order multifetal gestations increased by $400 \%$ between the 1980 s and 1990 s, peaking at 193.5 per 100,000 births in $1998 .^{2}$ This was followed by a modest decrease to 153.4 per 100,000 births by $2009 .^{2}$ The rate of multiple gestations accounted for $1 \%$ of total pregnancies in Japan. ${ }^{3}$

With an increasing number of fetuses, the rates of fetal and maternal complications become significantly higher. For the mother, the risks include gestational diabetes, hypertensive disease, renal disease, cardiovascular disease, emotional difficulties, and financial pressure. ${ }^{4-7}$ There is also a higher risk of received

February 2, 2020

accepted

April 24, 2020
DOI https://doi.org/

10.1055/s-0040-1715167. ISSN 2157-6998.
Copyright $\odot 2020$ by Thieme Medical

Publishers, Inc., 333 Seventh Avenue, New York, NY 10001, USA. Tel: +1(212) 760-0888.
License terms

(ㅇ)(1) $\Theta \circledast$ 
pregnancy loss, fetal growth restriction, preterm delivery, and of complications associated with preterm delivery, such as respiratory disease and cerebral palsy.,9

Multi-fetal pregnancy reduction is widely used to decrease fetal and maternal risk during birth. ${ }^{10,11}$ Substantial data regarding multifetal pregnancy reduction (MFPR) for twin and triplet pregnancies have been reported ${ }^{12-14}$; however, studies of higher order multifetal pregnancy (quadruplets and greater) are limited because of their relative rarity compared with twins and triplets. Abel and coworkers reported 40 cases of triplets, 10 cases of quadruplets, and no cases of quintuplets. ${ }^{15}$ In the study by Fajolu et al, there were 15 cases of triplets, 6 cases of quadruplets, and only one case of quintuplets reported. ${ }^{8}$ In another study, there were 35 cases of quadruplets, 11 of quintuplets, 1 of sextuplets, and 1 of septuplets reported. ${ }^{16}$ To understand the risks, we conducted a single-center, retrospective study of a large population of women who underwent higher order multifetal pregnancy reduction including 104 cases of quadruplets, 20 cases of quintuplets, 5 cases of sextuplets, 1 case of septuplets, and 1 case of octuplets. To our knowledge, the present study includes considerably more quadruplets and overall cases with multiple fetuses from a single-center compared with previous studies.

\section{Materials and Methods}

\section{Study Participants}

Between January 2005 and December 2015, 131 higher order multiple pregnancy patients were admitted to the department of Obstetrics and Gynecology, Provincial Hospital Affiliated to Shandong University. This institution is a referral center located in a large metropolitan area. The department of Obstetrics and Gynecology is affiliated with the division of maternal-fetal medicine and consultants. The first case of MFPR in the Republic of China was performed during the second trimester in this institution. Our center also has the largest division of maternal-fetal medicine and cases of MFPR in China. As such, numerous multiple pregnancy patients are referred to this institution. All higher order pregnancies were induced by ART, and MFPR was performed at 11 to 18 weeks of gestation in all cases. The control group consisted of 101 pregnancies with nonreduced twins. Theses 101 patients received prenatal care and delivered in the department of Obstetrics and Gynecology, Provincial Hospital Affiliated to the Shandong University between January 2013 and December 2015.

\section{Procedure}

Informed consent was obtained, and the risks associated with higher order multifetal pregnancy and the operational procedure for reducing the number of fetuses were explained to all participants and their spouses. Participants then made a final decision and provided informed signed consent. The study was approved by the ethics committee of the Provincial Hospital Affiliated to Shandong University.

Depending on the number of fetuses, the MFPR was performed over one to three sessions. Two or three fetuses were reduced per session. If two or three sessions were required to complete the procedure, the subsequent session was planned 5 to 7 days later. In cases where multifetal reduction to twins was recommended, maternal preference was the final determination factor.

In all higher order multifetal pregnancies, the reduction procedure was undertaken 24 to 72 hours after a detailed combined transvaginal and transabdominal examination of fetal size. Anomalies and nuchal translucency (NT) were evaluated by an experienced sonographer (a consultant in fetal medicine). If a fetal anomaly or an increased risk of chromosomal or structural malformation was suspected, the fetal reduction was targeted selectively to the impacted fetus. If no fetal anomaly was suspected, the smaller sac/sacs or the sac/sacs proximal to the uterine fundus were considered. To preserve a healthy pregnancy outcome, fetal and maternal factors were taken into account while selecting the target fetus/fetuses for reduction.

Ultrasound-guided transabdominal intracardiac injection of potassium chloride $(\mathrm{KCl})$ was administered by the same surgeon. The techniques used and follow-up treatments have been described elsewhere. ${ }^{17}$

\section{Outcome Measures}

Based on the patient's medical records, the gestation period was established. The following types of pregnancy loss were recorded: (1) abortions (up to 4 weeks after fetal reduction and before 28 weeks of gestation) and (2) intrauterine fetal death (up to 28 weeks of gestation). We calculated the delivery rate at 28 to $33\left(+{ }^{6 / 7}\right)$ weeks, delivery rate at 34 to $36\left(+{ }^{6 / 7}\right)$ weeks, mean gestational age at delivery, mean birth weight, and the rate of birth-weight discordance (BWD), which is the difference in the birth weight of twins. BWD was calculated by larger weight - the smaller weight/larger weight. While there was no consensus on the precise threshold of BWD that might be associated with complications, the American College of Obstetricians and Gynecologists (ACOG) considers a 15 to $25 \%$ difference in weight between twins to be discordant. ${ }^{18}$ We defined a difference of more than $20 \%$ as discordant. The incidence of gestational diabetes and pregnancy-induced hypertension in cases reduced to twins and nonreduced cases was also recorded.

\section{Statistical Analyses}

All statistical analyses were performed using SPSS (version 25.0; SPSS, Chicago, IL). A probability of 0.05 was considered statistically significant. Descriptive statistical methods were used to evaluate the outcomes of MFPR. Chi-square and Fisher's exact tests were used to compare pregnancy loss rate, delivery rate at 28 to $33\left(+{ }^{6 / 7}\right)$ weeks, delivery rate at 34 to 36 $\left(+{ }^{6 / 7}\right)$ weeks, the rate of BWD, and the incidence rate of both gestational diabetes and pregnancy-induced hypertension. The independent $t$-test was used to compare mean gestational age at delivery and mean birth weight in the two groups.

\section{Results}

with higher order multi-fetal pregnancy (including 104 sets of quadruplets, 20 quintuplets, 5 sets of sextuplets, 1 set of septuplets, and 1 set of octuplets). MFPR was performed at 11 
e230 Safety and Efficacy of Higher Order Multifetal Pregnancy Reduction Liu et al.

Table 1 Higher-order multi-fetal pregnancy reduction

\begin{tabular}{|l|l|l|l|}
\hline $\begin{array}{l}\text { Staring } \\
\text { number of } \\
\text { fetuses }\end{array}$ & $\begin{array}{l}\text { Number of } \\
\text { patients }\end{array}$ & $\begin{array}{l}\text { Number of } \\
\text { sessions }\end{array}$ & $\begin{array}{l}\text { Number of } \\
\text { fetuses after } \\
\text { MFPR }\end{array}$ \\
\hline 4 & 104 & 1 & $2(104$ cases $)$ \\
\hline 5 & 20 & $1-2$ & $\begin{array}{l}1(1 \text { case }) \\
2(14 \text { cases }) \\
3 \text { (5 cases })\end{array}$ \\
\hline 6 & 5 & $\begin{array}{l}1-2 \\
1 \text { case lost } \\
\text { after the first } \\
\text { session }\end{array}$ & $\begin{array}{l}\text { (3 cases }) \\
(1 \text { case })\end{array}$ \\
\hline 7 & 1 & $\begin{array}{l}3 \\
\text { lost after the } \\
\text { third session }\end{array}$ & 1 case $)$ \\
\hline 8 & 1 & 3 & $2(1$ case $)$ \\
\cline { 2 - 4 } & $131^{*}$ & & \\
\cline { 2 - 4 } & $102^{\&}$ & & \\
\hline
\end{tabular}

"The total number of higher-order multiple pregnancy.

${ }^{\&}$ The number of reduced to twins among all higher-order multi-fetal reduction.

to 18 weeks of gestation in all cases. One hundred and twenty-two cases were reduced to twins (in China, with the effect of the family plan policy, couples preferred to have two babies in one delivery), three cases were reduced to a single fetus, five cases were reduced to triplets, and one patient pregnant with sextuplets experienced a miscarriage after the first session (-Table $\mathbf{1}$ ).

One hundred and four cases of quadruplets were reduced to twins. The rate of pregnancy loss, preterm deliveries at 28 to 33 $\left(+{ }^{6 / 7}\right)$ weeks and preterm deliveries at 34 to $36\left(+{ }^{6 / 7}\right)$ weeks was $20.19,7.22$, and $38.55 \%$, respectively. The mean delivery time was $36.71 \pm 1.64$ weeks, and the mean birth weight was $2,450.42 \pm 438.88 \mathrm{~g}$. In regard to the quintuplets, 1 case was reduced to a single fetus, 14 cases were reduced to twins, and 5 cases were reduced to triplets. The rate of pregnancy loss, preterm deliveries at 28 to $33\left(+{ }^{6 / 7}\right)$ weeks and preterm deliveries at 34 to $36\left(+{ }^{6 / 7}\right)$ weeks was 40,25 , and $25 \%$, respectively. The mean delivery time was $36.09 \pm 2.60$ weeks, and mean birth weight was 2,144.62 $\pm 544.31 \mathrm{~g}$. Among five sets of sextuplets, one case was reduced to a single fetus, and three cases were reduced to twins. Only one case resulted in miscarriage after the first session, and one set of sextuplets was delivered at 34 to $36\left(+{ }^{6 / 7}\right)$ weeks. One patient pregnant with septuplets underwent three sessions of MFPR which resulted in preterm loss after the third session. One set of octuplets was reduced to twins after three sessions of reduction. Delivery was performed at 35 weeks and both babies survived (-Table 2 ).

Compared with 101 cases of nonreduced twins, the pregnancy loss rate for reduced twins when MFPR was performed at 11 to $14\left(+{ }^{6 / 7}\right)$ gestational weeks or after 15 gestational weeks was found to be significantly higher. The preterm labor rate, delivery weeks and mean birth weight, BWD rate, incidence of gestational diabetes, and pregnancy-induced hypertension were not significantly different between groups ( $p>0.05$; - Table 3$)$.

\section{Discussion}

Number of several studies on twins and triplets have reported fetal reduction in multifetal pregnancy. ${ }^{13,14}$ Limited reports are available from studies of quadruplets in comparison, ${ }^{10-12}$ and fewer reports are available on higher order multifetal pregnancy. $8,15,16$ Many studies have reported higher order multifetal pregnancy reduction but often they are neither conducted in single centers nor performed by the same physician. Our study included a lager sample size of 131 patients comprising 104 sets of quadruplets, 20 sets of quintuplets, 5 sets of sextuplets, 1 set of septuplets, and 1 set of octuplets. Most importantly, the procedure was performed by a single physician at a single center. This makes the outcomes of this study more reliable for use as a reference while conducting prenatal counseling.

For pregnancies involving quintuplets or multiple fetuses, it is best to perform multiple procedures where two or three fetuses are targeted in one session. That way, a sudden decrease

Table 2 The outcomes of higher-order multi-fetal pregnancy reduction

\begin{tabular}{|c|c|c|c|c|c|c|}
\hline \multirow{2}{*}{$\begin{array}{l}\text { Starting } \\
\text { number } \\
\text { of fetuses }\end{array}$} & \multirow{2}{*}{$\begin{array}{l}\text { Number of } \\
\text { patients }\end{array}$} & \multirow{2}{*}{$\begin{array}{l}\text { Pregnancy } \\
\text { Loss (\%) }\end{array}$} & \multicolumn{2}{|c|}{ Preterm laboue(\%) } & \multirow{2}{*}{$\begin{array}{l}\text { Delivery } \\
\text { weeks (range) }\end{array}$} & \multirow{2}{*}{$\begin{array}{l}\text { Fetal weight }(\mathrm{g}) \\
\text { (range, } n \text { : number } \\
\text { of fetuses) }\end{array}$} \\
\hline & & & $\begin{array}{l}28-33^{+6 / 7} \\
\text { weeks } n(\%)\end{array}$ & $\begin{array}{l}34-36^{+6 / 7} \\
\text { weeks } n(\%)\end{array}$ & & \\
\hline 4 & 104 & $21(20.19)$ & $6(7.22)$ & $32(38.55)$ & $\begin{array}{l}36.71 \pm 1.64 \\
(31.86-40.00)\end{array}$ & $\begin{array}{l}2450.42 \pm 438.88 \\
(1300-3500, n=166)\end{array}$ \\
\hline 5 & 20 & $8(40)$ & $3(25)$ & $3(25)$ & $\begin{array}{l}36.09 \pm 2.60 \\
(31.00-39.57)\end{array}$ & $\begin{array}{l}2144.62 \pm 544.31 \\
(1160-3400, n=26)\end{array}$ \\
\hline 6 & 5 & $1(20)$ & - & $1(25)$ & $\begin{array}{l}37.11 \pm 0.43 \\
(36.71-37.71)\end{array}$ & $\begin{array}{l}2364.29 \pm 241.03 \\
(2050-2700, n=7)\end{array}$ \\
\hline 7 & 1 & $1(100)$ & - & - & - & - \\
\hline 8 & 1 & - & - & $1(100)$ & 35 & $\begin{array}{l}2100 \\
(2000,2200, n=2)\end{array}$ \\
\hline Total & 131 & $31(23.66)$ & $9(9)$ & $37(37)$ & $\begin{array}{l}36.56 \pm 1.77 \\
(31.00-40.00)\end{array}$ & $\begin{array}{l}2409.90 \pm 458.16 \\
(1160-3500, n=301)\end{array}$ \\
\hline
\end{tabular}


Table 3 Reduced to twins among all higher-order multi-fetal pregnancy VS non-reduced twins

\begin{tabular}{|c|c|c|c|c|}
\hline & \multicolumn{2}{|c|}{ Reduced to twins } & \multirow[t]{2}{*}{ Non-reduced twins } & \multirow[t]{2}{*}{$P$} \\
\hline & $11-14^{+6}$ weeks & $\geq 15$ weeks & & \\
\hline Number of patients & 93 & 29 & 101 & NS \\
\hline Maternal age (years) & $29.09 \pm 3.26$ & $29.2 \pm 4.21$ & $29.35 \pm 4.49$ & NS \\
\hline Parity & $1.65 \pm 0.76$ & $1.59 \pm 0.77$ & $1.84 \pm 0.77$ & $0.014 £ 0.049^{\#}$ \\
\hline Pregnancy loss (\%) & $20(21.50)$ & $7(24.14)$ & $9(8.91)$ & $0.038^{\S}$ \\
\hline$<24$ weeks $(n)$ & 13 & 6 & 7 & NS \\
\hline $24-27^{+6 / 7}$ weeks $(n)$ & 7 & 1 & 2 & NS \\
\hline Preterm labour weeks (\%) & $33(45.20)$ & $8(36.36)$ & $39(42.39)$ & NS \\
\hline $28-33^{+6 / 7}$ weeks $(n)$ & 7 & 1 & 5 & NS \\
\hline $34-36^{+6 / 7}$ weeks $(n)$ & 26 & 7 & 34 & NS \\
\hline Gestational age at delivery (wk) & $36.60 \pm 1.78$ & $36.99 \pm 1.33$ & $36.43 \pm 1.57$ & NS \\
\hline Mean birth weight $(g) n=374$ & $2417.77 \pm 462.76$ & $2461.90 \pm 381.24$ & $2427.26 \pm 473.64$ & NS \\
\hline Mean high birth weight $(\mathrm{g}) n=187$ & $2536.22 \pm 451.15$ & $2604.76 \pm 361.22$ & $2581.96 \pm 434.83$ & NS \\
\hline Mean low birth-weight (g) $n=187$ & $2299.32 \pm 446.37$ & $2319.05 \pm 462.24$ & $2272.55 \pm 462.23$ & NS \\
\hline Birth-weight discordance (\%) & $7(9.59)$ & $2(9.09)$ & $13(14.1)$ & NS \\
\hline Gestational diabetes mellitus (\%) & $4(5.48)$ & $1(4.55)$ & $2(2.17)$ & NS \\
\hline Pregnancy-induced hypertension (\%) & $9(12.33)$ & $2(9.09)$ & $7(7.60)$ & NS \\
\hline
\end{tabular}

£ Comparison between reduced to twins when MFPR were performed at $11-14^{+6}$ weeks and non-reduced twins.

\# Comparison between reduced to twins when MFPR were performed after 15 weeks and non-reduced twins.

$\S$ Comparison between reduced to twins when MFPR were performed after 15 weeks and non-reduced twins.

of uterine volume can be avoided. The subsequent session should be planned after 5 to 7 days of postoperative observation.

The greatest risk of higher order multiple pregnancies is associated with a higher risk of fetal loss and pregnancy loss. Dicey and coworkers reported that at least $53 \%$ of triplets and $65 \%$ of quadruplets will result in spontaneous reduction of one or more fetuses. ${ }^{19}$ They found that pregnancy loss occurred in 12 to $16 \%$ of cases at 24 weeks for triplets and before 24 weeks' gestation for multiple fetuses. ${ }^{20}$ In this study, pregnancy loss was defined as abortions (up to 4 weeks after fetal reduction and before 28 weeks of gestation), and intrauterine fetal death (up to 28 weeks of gestation). All cases in this study resulted in fetal reduction. The pregnancy loss rate for quadruplets, quintuplets, and sextuples was $20.19,40$, and $20 \%$, respectively. Loss of a set of septuplets after the third session was also documented. The results suggest that with an increasing number of fetuses, the pregnancy loss rate also increases.

The comparison between reduced twins and nonreduced twins showed a significant difference in pregnancy loss rate, which is in contrast to previous findings where no difference was noted between the two groups. ${ }^{21,22}$ In our study, the pregnancy loss rate in reduced twins was higher than reported in previous studies. This is primarily due to three factors. First, in earlier studies, more triplets and multiple pregnancies were included. Our study included quadruplets and multiple fetuses. Pregnancy loss depended not only on the surgical operator's experience but also on the starting number of fetuses, and the number of fetuses reduced. ${ }^{23,24}$ Second, among the 122 cases that were reduced to twins, only 15 underwent MPRF at 11 weeks of gestation. Most cases in previous studies underwent MFPR in the second trimester. Third, spontaneous abortion was defined as before 24 weeks in previous studies and as before 28 weeks in this study (according to the Chinese Ministry of Health). Some babies who were born at 24 to 28 weeks were abandoned to rescue.

In this study, preterm deliveries at 28 to $33\left(+{ }^{6 / 7}\right)$ weeks and preterm deliveries at 34 to $36\left(+{ }^{6 / 7}\right)$ weeks were observed in 9 and $37 \%$ of cases, respectively. The mean time of delivery and mean birth weight of the 131 cases was $36.56 \pm 1.77$ weeks and $2,409.90 \pm 458.16 \mathrm{~g}$, respectively. Preterm delivery is inversely related to the number of fetuses in utero. ${ }^{25}$ The main gestational age at delivery is 40 weeks for single fetuses, 35 to 37 weeks for twins, 33 weeks for triplets, and 29 weeks for quadruplets. ${ }^{25}$ There is similar risk in gestational age during delivery and main birth weight. ${ }^{26}$ According to the National Center for Vital Statistics, the average birth weight for triplets, quadruplets, and higher order gestations was 1,666, 1,371, and 1,253 g, respectively. $^{26}$ The risk of cerebral palsy also increased with fetal number, and is related to gestational age and birth weight at time of delivery. ${ }^{27}$ The results of our study suggest that perinatal outcomes were significantly improved by reducing the number of fetuses. One hundred and twentytwo cases of reduced twins were compared with nonreduced twins. Preterm labor rate, delivery weeks, and mean birth weight were not significantly different between groups. Results from our study are similar to previous studies and suggest that reducing the number of fetuses did not increase the rate of preterm labor and birth weight. ${ }^{21,22}$ 
We defined BWD as a more than $20 \%$ difference in weight between twins. In a previous study, multifetal pregnancies with at least one growth-restricted fetus were found to be associated with a 7.7-fold increased risk of major neonatal morbidity. ${ }^{28}$ In another study, the rate of BWD in twins born in the group with triplets and higher order multiples was $13.9 \%{ }^{12}$ In our study, the BWD was $9.59 \%$ when MFPR was performed at 11 to $14\left(+{ }^{6 / 7}\right)$ gestational weeks and $9.05 \%$ when MFPR was performed after 15 gestational weeks. Therefore, our results show an improvement compared with the previous study.

Women with higher order multiple pregnancies are at increased risk for pregnancy-associated complications during pregnancy and delivery. This is supported by a previous study that characterized the association between higher order multiples and gestational diabetes, pregnancy-induced hypertension, and anemia hemorrhage. ${ }^{29}$ In this study, the incidence rate of gestational diabetes and pregnancy-induced hypertension for reduced twins from higher order multiples was 5.48 and $12.33 \%$, respectively, when MFPR was performed at 11-14 ${ }^{(+6 / 7)}$ weeks of gestation and 4.55 and $9.09 \%$, respectively, when MFPR was performed after 15 weeks of gestation. Compared with cases that did not undergo reduction, the result was not statistically significant. Therefore, reducing fetuses did not increase the rate of gestational diabetes or pregnancy-induced hypertension in women with multiple pregnancies.

\section{Limitations and Conclusion}

The majority of patients were transferred from outside the institution. We were not able to collect any data with regard to previous pregnancies in these patients. Our study also lacks adequate information on medical history, such as infertility treatment type. The study included a limited number of cases of sextuplets and beyond, and hence we speculate a reasonable bias in the results. However, there were a significant number of quadruplets and quintuplets included. In addition, this was a retrospective study, which means that confounding factors may have had an impact on overall outcomes and data interpretation.

Our study shows that perinatal outcomes were vastly improved by reducing the number of fetuses in higher order multifetal pregnancy. This single-center study involved a large and diverse sample size of 131 consecutive patients with higher order multifetal pregnancy (104 sets of quadruplets, 20 sets of quintuplets, 5 sets of sextuplets, 1 set of septuplets, and 1 set of octuplets). The results of this study can be used as a reference while conducting prenatal counseling.

Conflict of Interest

None declared.

\section{References}

1 Chia KS, Lee JJ, Cheung P, et al. Twin births in Singapore: a population-based study using the National Birth Registry. Ann Acad Med Singapore 2004;33(02):195-199

2 Martin JA, Hamilton BE, Ventura SJ, et al. Births: final data for 2009. National vital statistics reports: from the Centers for
Disease Control and Prevention, National Center for Health Statistics. Natl Vital Stat Syst 2011;60:1-70

3 Ooki S. Estimation of the contribution of assisted and nonassisted reproductive technology fertility treatments to multiple births during the past 30 years in Japan: 1979-2008. Twin Res Hum Genet 2011;14(05):476-483

4 Sivan E, Maman E, Homko CJ, Lipitz S, Cohen S, Schiff E. Impact of fetal reduction on the incidence of gestational diabetes. Obstet Gynecol 2002;99(01):91-94

5 Luke B, Brown MB. Contemporary risks of maternal morbidity and adverse outcomes with increasing maternal age and plurality. Fertil Steril 2007;88(02):283-293

6 Sheard C, Cox S, Oates M, Ndukwe G, Glazebrook C. Impact of a multiple, IVF birth on post-partum mental health: a composite analysis. Hum Reprod 2007;22(07):2058-2065

7 Bailit JL. Hyperemesis gravidarium: epidemiologic findings from a large cohort. Am J Obstet Gynecol 2005;193(3, Pt 1):811-814

8 Fajolu IB, Ezeaka VC, Adeniyi OF, Iroha EO, Egri-Okwaji MTC. Prevalence and outcome of higher order multiple pregnancies in Lagos, Nigeria. J Matern Fetal Neonatal Med 2013;26(13): 1342-1345

9 Pharoah POD. Risk of cerebral palsy in multiple pregnancies. Clin Perinatol 2006;33(02):301-313

10 Evans MI, Andriole S, Britt DW. Fetal reduction: 25 years' experience. Fetal Diagn Ther 2014;35(02):69-82

11 Antsaklis A, Anastasakis E. Selective reduction in twins and multiple pregnancies. J Perinat Med 2011;39(01):15-21

12 Evans MI, Berkowitz RL, Wapner RJ, et al. Improvement in outcomes of multifetal pregnancy reduction with increased experience. Am J Obstet Gynecol 2001;184(02):97-103

13 Evans MI, Kaufman MI, Urban AJ, Britt DW, Fletcher JC. Fetal reduction from twins to a singleton: a reasonable consideration? Obstet Gynecol 2004;104(01):102-109

14 Lopes Perdigao J, Straub H, Zhou Y, Gonzalez A, Ismail M, Ouyang DW. Perinatal and obstetric outcomes of dichorionic vs trichorionic triplet pregnancies. Am J Obstet Gynecol 2016;214(05):659. e1-659.e5

15 Abel JS, Flöck A, Berg C, Gembruch U, Geipel A. Expectant management versus multifetal pregnancy reduction in higher order multiple pregnancies containing a monochorionic pair and a review of the literature. Arch Gynecol Obstet 2016;294(06): 1167-1173

16 Cihangir Yılanloglu N, Semiz A, Arisoy R, Kahraman S, Arslan Gürkan A. The outcome of the multifetal pregnancy reduction procedures in a single centre: A report of 202 completed cases. Eur J Obstet Gynecol Reprod Biol 2018;230:22-27

17 Wang XT, Li HY, Feng H, et al. [Clinical study of selective multifetal pregnancy reduction in second trimester] (in Chinese). Zhonghua Fu Chan Ke Za Zhi 2007;42(03):152-156

18 American College of Obstetricians and Gynecologists Committee on Practice Bulletins-Obstetrics; Society for Maternal-Fetal Medicine; ACOG Joint Editorial Committee. ACOG practice bulletin \#56: multiple gestation: complicated twin, triplet, and high-order multifetal pregnancy. Obstet Gynecol 2004;104(04):869-883

19 Dickey RP, Taylor SN, Lu PY, et al. Spontaneous reduction of multiple pregnancy: incidence and effect on outcome. Am J Obstet Gynecol 2002;186(01):77-83

20 Regan L, Rai R. Epidemiology and the medical causes of miscarriage. Best Pract Res Clin Obstet Gynaecol 2000;14(05): 839-854

21 Hershko-Klement A, Lipitz S, Wiser A, Berkovitz A. Reduced versus nonreduced twin pregnancies: obstetric performance in a cohort of interventional conceptions. Fertil Steril 2013;99(01): 163-167

22 Nevo O, Avisar E, Tamir A, Coffler MS, Sujov P, Makhoul IR. Neonatal course and outcome of twins from reduced multifetal pregnancy versus non-reduced twins. Isr Med Assoc J 2003;5(04): $245-248$ 
23 Evans MI, Ciorica D, Britt DW, Fletcher JC. Update on selective reduction. Prenat Diagn 2005;25(09):807-813

24 Timor-Tritsch IE, Bashiri A, Monteagudo A, Rebarber A, Arslan AA. Two hundred ninety consecutive cases of multifetal pregnancy reduction: comparison of the transabdominal versus the transvaginal approach. Am J Obstet Gynecol 2004;191(06):2085-2089

25 Evans MI, Britt DW. Fetal reduction. Semin Perinatol 2005;29(05): 321-329

26 Martin JA, Hamilton BE, Sutton PD, Ventura SJ, Mathews TJ, Osterman MJ. Births: final data for 2008. Natl Vital Stat Rep 2010;59(01):1-71, 3-71
27 Wadhawan R, Oh W, Vohr BR, et al; Eunice Kennedy Shriver National Institute of Child Health \& Human Development Neonatal Research Network. Neurodevelopmental outcomes of triplets or higher-order extremely low birth weight infants. Pediatrics 2011;127(03):e654-e660

28 Yinon Y, Mazkereth R, Rosentzweig N, Jarus-Hakak A, Schiff E, Simchen MJ. Growth restriction as a determinant of outcome in preterm discordant twins. Obstet Gynecol 2005;105(01):80-84

29 Lemos EV, Zhang D, Van Voorhis BJ, Hu XH. Healthcare expenses associated with multiple vs singleton pregnancies in the United States. Am J Obstet Gynecol 2013;209(06):586.e1-586.e11 